\title{
Establishment and Research on the Model of the Company's Financial Risk Warning Based on Principal Component Analysis and Logistic Regression
}

\author{
JingJing $\mathrm{Fu}^{1, \text { a }}$ \\ ${ }^{1}$ Henan Vocational and Techinical College of Communications, Zhengzhou, China \\ a122440757@qq.com
}

Keywords: Company's Financial Risk Warning, Principal Component Analysis, Logistic Regression

\begin{abstract}
In this paper, we use the modern management theory to build a corporate financial risk early warning indicator system, while using the statistical method of principal component analysis and logistic regression analysis. Through the empirical research on listed companies' financial crisis situation, we established the company's financial early warning model to provide a scientific and feasible prediction method for enterprises to predict the financial crisis.
\end{abstract}

\section{Introduction}

With the development of global economic integration, enterprises in access to economic resources, it is also under great pressure of fierce market competition. Uncertainties due to the risk of a variety of transactions increases, companies are facing the business and financial risks have increased. In order to be in an invincible position in the competition, the enterprise healthy and orderly development, effectively avoid, prevent and control risks to become a top priority for enterprise development. Establish and improve financial risk early warning system is a powerful tool for the prevention of financial risks. An effective financial risk early warning system can predict signs of financial crisis, and to discover the cause of the deterioration of the financial situation, enabling operators to take preventive and control measures before the crisis hit, the crisis in the bud. It can be seen that financial risk warning plays a very important role for the development of enterprises. Therefore, the establishment of financial early warning model, the early diagnosis of the financial crisis and take appropriate measures to maintain health and safety and sustainable development of enterprises, it is very important [1].

\section{The Establishment of Financial Early Warning Index System}

Modern financial management theory holds that measure a company's financial condition, depends on the company's solvency, asset management, profitability and ability to grow. Accordingly, the financial early warning indicators of enterprises can be divided into four categories: financial benefit status indicators, asset operating status indicators, solvency status indicators and development capacity status indicators. Including a number of financial ratios in each category indicators, these indicators reflect the financial position and operating results of the enterprise. The financial early warning system for corporate debt risk by asset management risk, earnings risk and growth monitoring of risk indicators constitute four categories [2].

\section{The Establishment of Corporate Financial Risk Early Warning Model}

The Selection of the Study Sample. Sample data is mainly from CCER generally listed companies' financial database system. Limit the reliability of sources of information and data by the study sample all from listed companies. In this paper, the standard sample selection:

(1)ST sample groups: the company between 2011 and 2012 since the financial situation but had to be specially treated as an exception ST sample group, and asked for two years before it was ST information. 
(2)Non-ST sample group: According be "ST" industry classification and the corresponding year corresponding to the selected control sample, that sample group of non-ST (healthy companies).

In order to meet the needs of this paper, we study a random sample of 100 listed companies as samples to build the model.

Select the Model Variables. Based on the characteristics of listed companies selected eight variables X1: ROE (operating profit) X2: ROE X3: net profit growth X4: Current Ratio X5: cash flow debt ratio X6: asset-liability ratio X7: accounts receivable turnover ratio X8 turnover.

The Establishment of Early Warning Models. Using SPSS statistical software, this 100 sample companies, according to the eight study variables identified above principal component analysis. The following results [3]:

The information on the eight indicators, when selected five main cause of midnight, the information reaches $94.302 \%$, which preserves the information of the original indicators. From Table 4, the rotated factor loading matrix, the first principal component FAC1_1 and X4: current ratio, X5: cash flow debt ratio, X6: the amount of factor loadings of these three indicators of asset-liability ratio is much larger than several other indicators, by these three variables to explain, reflecting the company's solvency. Therefore FAC1_1 represents corporate solvency main ingredient. FAC2_1 primarily by the variable X1: ROE (operating profit), X2: ROE two indicators to explain, these two indicators are all indicators of the profitability of the enterprise, so FAC2_1 on behalf of corporate profitability main ingredient. FAC3_1 main X8 by variables: turnover to explain, this indicator belongs operational capacity index, so FAC3_1 companies operating capacity on behalf of the main ingredients. FAC4_1 mainly by variable X7: accounts receivable turnover to explain this indicator belongs operational capacity indicators, it also represents the same FAC4_1 with FAC3_1 companies operating capacity main ingredient. FAC5_1 primarily by the variable X4: net profit growth to explain, this indicator also belong development capacity index, so FAC5_1 also represents the main component of business development capability. From the factor score coefficient matrix (Component Score Coef-ficient Matrix), the main component of the rotated factor expression can be written as: 10

FAC1_1=X1*(-0.099)-0.079*X2+X3*0.062+0.472*X6+0.46*X7-0.216*X8-0.028*X9-0.051*X

FAC2_1=0.869*X1+0.386*X2-0.173*X3-0.133*X4-0.14*X5-0.301*X6-0.032*X7+0.163*X8

FAC3_1=-0.441*X1+0.262*X2-0.065*X3-0.05*X4-0.03*X5+0.132*X6-0.044*X7-0.015*X8

FAC4_1=-0.071*X1-0.062*X2+0.071*X3-0.02*X4-0.032*X5-0.026*X6-0.009*X7-0.009*X8

FAC5_1=-0.067*X1-0.13*X2+1.099*X3+0.112*X4+0.063*X5+0.148*X6-0.133*X7-0.046*X8

Table 1 Variables in the equation

\begin{tabular}{|cc|c|c|c|c|c|c|}
\hline & & B & S.E. & Wald & df & Sig. & Exp(B) \\
\hline Step1 & FAC1_1 & -3.115 & 1.799 & 4.239 & 1 & 0.040 & 0.025 \\
& FAC2_1 & -7.153 & 2.805 & 7.059 & 1 & 0.008 & 0.001 \\
& FAC3_1 & 3.002 & 1.197 & 6.314 & 1 & 0.012 & 20.226 \\
& FAC4_1 & -3.208 & 1.574 & 4.153 & 1 & 0.042 & 12.454 \\
& FAC5_1 & -2.201 & 1.230 & 6.796 & 1 & 0.009 & 0.040 \\
constant & -1.134 & 1.060 & 4.042 & 1 & 0.044 & 0.041 \\
\hline
\end{tabular}

a The variables being entered in step 1:. FAC1_1, FAC2_1, FAC3_1, FAC4_1, FAC5_1. 
Therefore, the coefficient by "B" column in early warning model is:

$\mathrm{P}=1 / 1+\mathrm{e}-\mathrm{z}(\mathrm{Z}=-3.115 * \mathrm{FAC1} 11-7.153 * \mathrm{FAC} 21+3.002 * \mathrm{FAC3} 1-3.208 * \mathrm{FAC} 41-2.206 * \mathrm{FAC5} 1$ 1.134)

Where: $\mathrm{P}$ is the probability of listed companies facing financial crisis;

FAC1_1 represents corporate solvency principal component factors;

FAC2_1 on behalf of corporate profitability principal components factor;

FAC3_1 behalf of companies operating capacity principal component factor;

FAC4_1 representatives of enterprises operating capacity principal component factor;

FAC5_1 representatives the principal component factor of business development capability.

Accordingly, the financial situation of listed companies is mainly determined by these five principal components factor. The final model obtained by use here, you can on the financial situation of listed companies to predict when the predicted probability is greater than 0.5 , it concluded that it would happen two years after the financial crisis, the financial crisis does not occur otherwise infer after his two years [4].

The Warning Effects of Final Model. By Logistic regression analysis, we have come to predict the effect of this model which is shown in Table 7.

Table 2 Logistic regression prediction classification model

\begin{tabular}{|c|c|c|c|}
\hline \multirow{3}{*}{ Observed value } & \multicolumn{3}{|c|}{ Predicted value } \\
\hline & \multicolumn{2}{|c|}{$11 / 12$ if ST } & \multirow{2}{*}{$\begin{array}{l}\text { Percentage } \\
\text { of } \\
\text { correction }\end{array}$} \\
\hline & 11/12 Ram ST & 11/12 initialST & \\
\hline $\begin{array}{c}\text { step1 11/12 if ST 11/11 Ram ST } \\
\text { 11/12 initial ST } \\
\text { Total percentage }\end{array}$ & $\begin{array}{c}52 \\
3\end{array}$ & $\begin{array}{c}6 \\
39\end{array}$ & $\begin{array}{l}89.7 \\
92.9 \\
91.0\end{array}$ \\
\hline
\end{tabular}

a Cutting is 0.500 .

For Logistic regression results in 100 sample units, there are nine adjudged wrong. The financial crisis in which 42 companies, there are three adjudged wrong, the accuracy rate was 92.9\%; in 58 companies in the non-financial crisis, there are six adjudged wrong, accuracy rate of $89.7 \%$, the overall accuracy rate of $91 \%$ this is a very high prediction accuracy rate effect, indicating that the early warning model can be applied in practice, with high practical value.

\section{The Application of Financial Early Warning Models}

Using Logistic regression models constructed to eight companies in 2009 based on financial information, the relevant financial ratios were calculated, and the scores of financial data into the equation, then the resulting factor FAC1_1, FAC2_1, FAC3_1, FAC4_1, FAC5_1 substituted into the model, the final judgment results in Table 3.

Table 3 The enterprise financial crisis predicted probability

\begin{tabular}{|l|l|l|l|l|l|l|}
\hline enterprise & FAC1_1 & FAC2_1 & FAC3_1 & FAC4_1 & FAC5_1 & probability \\
\hline enterprise 1 & 6.55 & -0.38 & -0.52 & -0.17 & -0.22 & 0.0000 \\
\hline enterprise 2 & 8.42 & -0.92 & 0.31 & -1.9 & -0.55 & 0.0000 \\
\hline enterprise 3 & 6.02 & -0.88 & 0.03 & -0.71 & 0.13 & 0.1737 \\
\hline enterprise 4 & 5.77 & -0.64 & 0.47 & -1.24 & 0.21 & 0.0002 \\
\hline enterprise 5 & 6.90 & -0.92 & -0.25 & -1.89 & 0.35 & 0.9766 \\
\hline enterprise 6 & 0.20 & -0.43 & 0.26 & 1.97 & 0.24 & 0.9992 \\
\hline enterprise 7 & 3.55 & -0.20 & -0.04 & -0.21 & 0.05 & 0.0001 \\
\hline enterprise 8 & 7.5 & -0.17 & -0.52 & 0.35 & 0.02 & 0.0000 \\
\hline
\end{tabular}

As can be seen from the table, there are two companies (Enterprise 5 and 6 enterprises) into a 
financial crisis, which is consistent with the actual situation, to further verify the validity of the model. Common characteristics of these two companies is the capital gains rate is lower than the industry warning value, accounts receivable recovery time is too long, so that the net cash flow can not support normal business needs. But on the basis of their conduct in-depth analysis on financial indicators found two companies share common features - taking losses in recent years the company, so we can assume that two companies in crisis is the source of loss-making enterprises, corporate real earnings poor, not create incremental cash flow, resulting in business capital chain there is a big risk. Enterprises to overcome adversity, to avoid the occurrence of financial crises, we must first solve the problem is how to turn around, creating real profit and cash increments [5].

\section{Conclusions}

Financial risk management and control is an important part of corporate financial management. And in order to do a good job in managing financial risk, the first thing is the financial risk early warning and taking appropriate measures to avoid risks, making financial risks and losses that may cause to a minimum. In this paper, we combined the characteristics of the listed companies in various industries and on the basis of ensuring the reliability of financial indicators, building an early warning indicator system which can fully reflect the financial risk, the establishment of financial risk early-warning model, and do a validation analysis of the applicability of the model, thus ensuring the practicality of corporate financial risk warning and risk assessment.

\section{References}

[1] W.Q. Wu: Master Thesis of Guangdong Technology University Vol. 3 (2003) No 16, p.19-23

[2] H.Y. Liang: Friends of Accounting, Vol. 4 (2010) No 26, p. 53-54

[3] W.H. Beaver: Journal of Accounting Research, Vol. 9 (1996) No 20, p. 47-50

[4] Altman. E.I., Financial Ratios: Journal of Finance Vol. 9 (1968) No15, p.145-147

[5] Altman, E.I., Haldeman, R • C: Journal of Banking anti Finance Vol. 1 (1977) No10, p.70-78 